\title{
ALOYSIUS BERTRAND, Daniel, drame-ballade en trois actes
}

\section{Valentina Ponzetto}

\section{(2) OpenEdition}

\section{Journals}

\section{Édition électronique}

URL : http://journals.openedition.org/studifrancesi/15606

DOI : $10.4000 /$ studifrancesi. 15606

ISSN : 2427-5856

\section{Éditeur}

Rosenberg \& Sellier

\section{Édition imprimée}

Date de publication : 1 décembre 2018

Pagination : $511-512$

ISSN : 0039-2944

\section{Référence électronique}

Valentina Ponzetto, « ALoysius bertrand, Daniel, drame-ballade en trois actes », Studi Francesi [En ligne], 186 (LXII | III) | 2018, mis en ligne le 01 janvier 2019, consulté le 06 janvier 2021. URL : http://

journals.openedition.org/studifrancesi/15606 ; DOI : https://doi.org/10.4000/studifrancesi.15606

Ce document a été généré automatiquement le 6 janvier 2021.

\section{$\circledast \oplus \Theta \Theta$}

Studi Francesi è distribuita con Licenza Creative Commons Attribuzione - Non commerciale - Non opere derivate 4.0 Internazionale. 


\title{
ALOYSIUS BERTRAND, Daniel, drame- ballade en trois actes
}

\author{
Valentina Ponzetto
}

\section{RÉFÉRENCE}

ALOYSIUS BERTRAND, Daniel, drame-ballade en trois actes, introduction, établissement du texte et annotation par Jacques-Remi Dahan, Tusson, Du Lérot, 2017, 151 pp.

On oublie trop souvent qu'Aloysius Bertrand est l'auteur d'autre chose que Gaspard de la Nuit. Tout particulièrement, comme le rappelle Jacques-Remi Dahan en ouverture de son introduction au présent volume, il «nourrit pour le théâtre une véritable passion» et fut l'auteur de six pièces «qui appellent à faire porter une réflexion renouvelée sur cette part spécifique de la création bertrandienne» (p.7). La première partie de l'introduction reconstruit ainsi pour le lecteur les événements de la vie de Bertrand en parallèle avec la genèse de corpus théâtral sans fortune, dont seul un vaudeville en un acte, Le sous-lieutenant des hussards, connut une création sur scène le 30 mars 1832. Ce fut un four si retentissant qu'il n'y eut jamais de deuxième représentation. Les autres pièces sont, par ordre chronologique: Le poirier d'une académie de province, scène dialoguée publiée le 25 mai 1828 dans «Le Provincial»; Les Sigisbées parisiens, ébauche de pièce ou «roman-vaudeville»; Les Conversions, proverbe dramatique publié dans «Les Grâces» du 11 novembre 1833; Louise, ou un pensionnat de demoiselles, "drame vaudeville en un acte imité de Mme Campan» écrit vraisemblablement pour le Théâtre des JeunesElèves de Louis Comte et publié en 1923 d'après un manuscrit aujourd'hui perdu; et enfin Daniel «drame-ballade en trois actes». Pour reprendre les mots de son auteur mis en exergue du texte, ce dernier «n'est autre chose que l'histoire de Martin Waldeck et de ses frères, racontée par l'alchimiste dans L'Antiquaire de Walter Scott», mais avec des développements et surtout un dénouement personnels, aux échos faustiens.

2 C'est cet unique drame de Bertrand, inédit et jamais représenté, qui est ici publié grâce à la découverte par Jacques-Remi Dahan d'un manuscrit de copiste avec annotations 
autographes dans les fonds de la Houghton Library de l'Université de Harvard. La troisième partie de l'introduction décrit la précieuse trouvaille et retrace l'histoire du manuscrit, qui à la mort de la mère du poète passa aux mains de Jules Claretie, puis de Jules de Marsan, avant de disparaître pendant quarante ans après la vente de la bibliothèque de ce dernier en 1976 .

3 La partie centrale de l'introduction est consacrée au drame lui-même et à sa longue élaboration, qui connut trois versions et autant de refus par les comités de lecture de différents théâtres. D'abord, en 1835, une première version, intitulée Le Lingot d'or, "drame mêlé de chants en trois actes et en dix tableaux», fut proposée sans fortune au théâtre Comte. Un an plus tard, une version en quatre actes et un épilogue appelé Peeter Waldeck ou la Chute d'un homme, fut refusée par le Théâtre de la Gaîté sous le prétexte saugrenu qu'il s'agissait d'une imitation de l'allemand, mais plus probablement à cause d'un deuxième acte jugé faible et des longueurs qui font souhaiter aux rapporteurs des coupures et une réduction en trois actes. Enfin une troisième version, Daniel, effectivement en trois actes et "peut-être aussi profondément refondue» (p. 21) fut présentée en 1837 au théâtre de la Porte-Saint-Martin et finalement refusée par son directeur Harel, pourtant défenseur du drame romantique, à cause des «détails mystiques, des développements très gracieux mais froids», en somme d'une écriture certes très élégante, mais qu'il juge peu adaptée à son public (pp. 27-28).

En plus du texte intégral inédit de cette dernière mouture du drame, la présente édition comporte aussi d'intéressants appendices: l'histoire de Martin Waldeck par Walter Scott dans sa traduction de l'édition Furne 1830, et les rapports successifs des comités de lecture des théâtres, avec les réponses ponctuelles et piquées de Bertrand. Ce dossier, qui aurait à notre avis gagné à être davantage commenté et contextualisé dans le cadre des débats esthétiques du temps, ajoute des pages significatives au chapitre des difficiles rapports du théâtre romantique avec la scène et de ce qui pouvait être jugé «représentable» dans les années 1830.

De ce drame sombre et singulier on retiendra enfin l'ambition métaphysique, trop rare au théâtre selon le contemporain Essai sur le drame fantastique de Sand (1839), une écriture des limites et de l'hybridité, une prose ciselée et exigeante, que les contemporains condamnèrent trop vite comme peu adaptée à la scène, et surtout un texte enfin restitué au corpus d'un théâtre romantique sans doute mineur, certainement minoré par la rencontre manquée avec le public. Pour tout spécialiste de Bertrand ou du théatre romantique, ce volume s'impose comme un complément nécessaire au volume d'Æuvres complètes édité par Helen Hart Poggenburg (Champion, 2000) où le texte intégral n'avait pas pu figurer, faute de texte source. 